\title{
The Impact of External Communication Strategy on Blockchain Startups: Analysing the Case of Credits Blockchain Platform
}

Sadia Bruce

University of Málaga, Málaga, Spain

\section{ARTICLE INFO}

Keywords:

Fund-raising

External communications

Blockchain

Cryptocurrency

Trust-building

\begin{abstract}
Communication is always an important part of establishing a business' sense of direction and growth; information needs to be accessed by the receiver in an appropriate way and put across in a clear, impactful and engaging way so that it will have an effect on the user. This research paper gives a detailed review of external communication strategies in the blockchain industry and how startups could revise their strategies over time to build trust and reputation. Even if the blockchain industry is becoming the preferred choice for businesses to securely conduct transactions, not many blockchain projects find acceptance amongst investors. Blockchain projects focus on raising funds for their ventures at a stage where they seldom have a viable product and using unregulated means of fundraising like initial coin offerings (ICO) or initial exchange offerings (IEO) have in turn been used to accumulate capital for such projects. With trust depleting in these means of fundraising, blockchain are becoming increasingly aware of the need to tailor their communication with potential investors. In this study, we've conducted cross-sectional studies across two separate times, once in 2017-18 at the time ICOs found prominence and then later in 2021, exploring how external communication strategies were revised and improved upon over time to ensure success and favour amongst users and investors.
\end{abstract}

\section{Introduction}

External communication strategy is nowhere as important as it is in the context of the blockchain industry. The industry has seen its fair share of peaks and troughs in its trustbuilding efforts. As much as the hype around one of its applications, i.e., cryptocurrency, has remained volatile at best, the industry still needs a better way of transmitting information to its stakeholders largely in the sphere of its influence-customers, potential investors and shareholders, etc (Camilleri, 2016, p. 278-279). Although the conceptual basis for blockchain harks back several decades now, yet because of the haze of uncertainty it attracts, practitioners find it difficult to indulge in fundraising endeavours, convincing sceptics into potential customers. The industry is making strides by addressing and resolving such issues through cooperation along with collaboration with their stakeholders (Camilleri, 2016, p. 279).

\footnotetext{
* Corresponding author E-mail address: sadia.bruce92@gmail.com 
The technology has already revolutionised the financial world by introducing limitless transactions using smart ledgers and entries coupled into groups called "blocks", encrypted with process-intensive cryptography and a decentralised system of record-keeping that foregoes the need for regulatory authorities and intermediaries (Rosati \& Čuk, 2018). Ever since its first application with Bitcoin, the technology has only seen more prominence (Narayanan, et. al., 2016). Insurmountable amounts of capital wrought a startup culture to form around the teething industry, seeking favour with the public not using initial public offerings (IPOs) but rather its anachronism "initial coin offering" (ICOs) - a unique way of marketing shares to potential investors guaranteed by the same underlying technology that is used by the company's products. ICOs, and the crowdsourcing efforts around them, saw a meteoric rise in their acceptance in 2017. ICOs raised as much as \$462 million in June 2017 alone, a number that grew to $\$ 574$ million the following month (Barnett, 2017). What beggars belief is that not many investors know what they are doing and the business model has survived to play out till date.

This lack of insight into the constructs and concepts of ICOs has always plagued many companies leaving investors remarkably worried about whether their investments would be safe or not. It all boils down to the detrimental effects of an external communications strategy that stands lacking. The intrinsic lack of regulatory oversight (as advocated for by the blockchain technology itself), investors have always held speculative concerns whether their investments may turn out to feed the coffers of a scam setup or the company they're investing into may very well have poor intentions (Griffith, 2017).

ICOs offer digital assets to its investors, called "tokens," which allow any startup to raise funds from a diverse group of investors. These tokens are a unit of cryptocurrency that the startups float on a blockchain ledger like OpenLedger or Ethereum. The arbitrary value for the cryptocurrency is merely a matter of determining the worth of the networked ledger itself, eventually settled upon by the basic principles of supply and demand for that token. ICOs, in effect, convert these investors into participants vying to trade on their networked blockchain. Startups are attracted to the prospects of gaining capital funds quickly by joining in on the ICO bandwagon, and some fail dramatically to build the type of rapport necessary to favour their cause. Injecting trust into their ICOs appears to be the most important yet troublesome area of concern for such startups.

Quite incidentally, almost 59\% of ICOs failed in 2017, primarily because their product offering was either not needed or no major audience could find a reason to connect with the products being offered (Bourgi, 2018). Blockchain companies failed to put across a minimum viable product (MVP) and failed to raise funds as needed.

The world's first cryptocurrency, Bitcoin, and its underlying technology, the blockchain, were developed as a response to the vestigial "trust crisis" that had overwhelmed the world following predatory mortgage lending practices by financial institutions leading up to the 2008 financial crisis (De Filippi, et. al., 2020). Wall Street institutions and credit rating agencies were proclaimed "most duplicitous" (Mackey, 2011) and a technology promising elimination of the need for centralised institutions and intermediaries held merit and aroused excitement.

Blockchain revolutionised finance by introducing limitless transactions using smart ledgers and transactions coupled into groups called blocks, encrypted with process-intensive cryptography and a decentralised system of record-keeping foregoing the need for intermediaries (Narayanan, et. al., 2016), thereby allowing users to subject themselves to the authority of a decentralised system that was practically immutable and transparent, inculcating "trust" into the very fabric of its design. However, academics seldom looked at this central property of the blockchain in a positive light. A decade later, what was once touted as "a 'trustless' alternative to existing financial institutions and even governments", 
faces a trust dilemma of its own (De Filippi, 2020). Around $45 \%$ of the respondents in the PricewaterhouseCoopers (PwC) 2018 Global Blockchain Survey, ranked "lack of trust among users" as one of the top barriers to blockchain adoption. The study concluded that it was mostly due to the people finding blockchain "foreign" and unfamiliar (PwC, 2018, as cited in Green, 2019).

External communication strategy is nowhere as important as it is in the context of the blockchain industry - an industry that has seen a fair share of ups and downs in its trustbuilding efforts. As much as the hype around cryptocurrency, one of blockchain's foremost applications, has remained volatile at best, the industry needs better ways of communicating with its stakeholders - customers, potential investors, etc. Where a distinct startup culture is building around the industry as a result of insurmountable capital flowing through, the uncertainty the industry attracts leaves practitioners finding it difficult to raise funds for these ventures convincing sceptics into potential customers.

\subsection{The problem with ICOs}

Unlike traditional businesses that generate capital through initial public offerings (IPOs), the blockchain industry uses initial coin offerings (ICOs), guaranteeing returns through mechanics built into the blockchain itself. ICOs, and the crowdsourcing efforts around them, saw a meteoric rise in their acceptance in 2017 (Pietrewicz, 2018) with ICOs raising as much as $\$ 462$ million in June 2017 alone - a number that grew to $\$ 574$ million the following month (Barnett, 2017) and then to \$3 billion in the first two months of 2018 (Lichfield, 2020). ICOs appear to sound like IPOs but unlike IPOs, investors are not offered shares in a company but rather tokens. Tokens are blockchain-based assets advertised to provide a way for investors to buy some amount of product or service that the blockchain company has yet to build at some point in the future.

There is no specificity when it comes to what amount of a product or service could be bought with the amount of tokens an investor has, or even if the products or services themselves had already been explicitly described, because the company has yet to carve these out. The biggest concern with ICOs has always been their lack of clarity and a highly speculative nature. Setting up an ICO requires that the blockchain startup owns a website, has written a whitepaper detailing roadmaps for product development, a crypto wallet and not much more. Whitepapers, however, "bamboozle" people and not many investors "can discern which technical claims (within these whitepapers) are sound and which aren't" (Lichfield, 2020). Whitepapers written specifically for ICOs were complex to extract relevant information from (Samieifar \& Baur, 2021). This is how fraud naturally permeates crypto projects with fraudulent ICOs making up almost $81 \%$ of all ICOs ever conducted. Brown (2018) notes that most of the non-fraudulent ICOs are ordinary business projects that are easier to understand and have detailed visions presented in a simpler language.

Most ICOs fail to communicate to their investors the relevance of their product offerings and the real functional economy encompassing their tokens. It was identified that almost $\$ 1.5$ million were stolen from potential investors each month by ICO proceedings that could be classified as either scams or phishing efforts by hackers (Bourgi, 2018). Almost 80\% of ICOs were at one point classified as scams while only $8 \%$ managed to reach the trading stages (Seth, 2018).

For companies that fail in the initial stages of an ICO, this dramatic loss can only be attributed to a poorly-constructed communication strategy that is not based on actual market research, an understanding of their investors and stakeholders or the nature of their own businesses.

Given the nature of the blockchain technology and the industry being in its infancy, there isn't enough information on what constitutes an effective external communication strategy 
for such businesses (McCann, 2017). It therefore becomes rather pertinent to devise a new external communication strategy for such endeavors that can consolidate the various aspects of blockchain startups and marketing communication in the mix. McCann explains that with each new ICO, "teams learn best practices on what to do and what not to do" (McCann, 2017) and it is in this spirit that the researcher has proposed to formulate a model external communication strategy for ICOs and its proceedings.

\subsection{Utility versus security}

Security tokens drive their value from external assets that can be traded while utility tokens are user tokens or called as app coins. Security tokens are subject to federal laws that govern security and it is mandatory for these tokens to comply with these regulations. If they fail to comply with these regulations then it'll lead to severe consequences such as penalties and potentially derailment of the development of the project.

In contrast to security tokens, utility tokens are given out during crowdsales as a project executes an ICO. The purpose of creating an utility token is to create a form of digital coupon that can be redeemed in the future for special access to a product or service that is offered by the company. These tokens are not used as investment securities, they can be exempted from the federal laws governing securities if they are properly set up.

These tokens can be distinguished based on the intended use and functionality. Security tokens are created as investments while utility tokens are not. Security tokens give ownership of the company to those users who hold these tokens. Security token offering (STO) is built to increase the trust of the investors and give reliability to them to invest in more projects (Sharma, 2019).

\subsection{The Credits platform}

The Credits platform was envisioned in 2017 as a decentralised, peer-to-peer payments processing platform allowing for delivery of financial services between parties through a distributed ledger and self-executing contracts supplemented by the Credits (CS) token, a cryptocurrency native to its blockchain. Contemporary blockchain payment processing was slow and the Credits platform sought to build a system capable of high execution speeds with hundreds of thousands of simultaneous transactions being conducted every second at a marginally low cost per transaction. The system also aimed at combining decentralised qualitative financial services like user identification, $\mathrm{KYCs}$, credit history bureaus, settlement centres for fiat money, withdrawal and liquidation of cryptocurrencies, etc., making it easier for developers making use of the platform to build fully-featured distributed applications (dApps).

As much as the project was technical in nature and primarily aimed at developers to make use of the platform as they saw fit, the documentation for the project was just as complicated to consume for an average investor. In a study conducted regarding the effectiveness of the communication for the platform in its earlier days (pre-ICO and during the proceedings of the ICO), it became effectively clear that the platform needed to diversify and simplify its messaging across the various channels of communication it used. Since then, the company employed significant external communications strategies that helped solidify its reach across its consumerbase. This study looks into the challenges faced by the company to make its platform more accessible and easier to understand.

\section{Methods}

This study aims to calculate how external strategies are formulated into favourable outcomes based on the phase of any given blockchain project from the startup's initial ICO efforts through to the final product development phase. What started off as a measurement of the 
effectiveness of these external communication strategies, e.g., whether direct marketing via email helped startups increase their project's adoption rates or how they managed to target potential investors, to an investigation into how these strategies eventually diverge and become completely different with time.

\subsection{Research focus}

As is evident later in this study, trust-building became an essential need for the company when they started their ICO proceedings. It meant that Credits had to approach their target audience of investors and stakeholders and establish a personal relationship with them first with direct telephone calls, and then via emails. The study also explores how Credits used these channels to bring clarity to the otherwise tiresome jargon used by the industry ad nauseum and the various factors that helped to influence the decisions of the investors and traders investing in their platform.

In order to conduct a comprehensive analysis of various external communication strategies used at Credits, a cross-sectional analysis can be made of the strategy and focus mostly on whether or not that communication strategy was effective and efficient. According to the surveys, interviews and other analytical parameters, it is simply shown that Credits managed to communicate with their targeted audience really well. Also, the google analytics and questionnaire results, they both possess the same parameters and give the approximate close results which state that the potential audience has been approached via different communication channels.

Credits increased their publications after completing their public crowd sale which helped bring more awareness to the project to its potential investors. It is necessary to know your audience and proper medium of communication to approach them. Firstly, it is important to build their trust, that their investment is secure with this blockchain project. Second is the uniqueness of the project, how good this project is. The technical documents that need to be sent to investors and other stakeholders so that they will get to know about your project. Third thing is a great public relations campaign in which one should involve all the possible channels to approach the potential investors, especially by getting to know their needs and the specificities their product may be able to solve. For such startup projects, it is quite vital to create a positive impact on the investors, done primarily through trust-building and positive enforcement of the brand.

\subsection{Research objectives}

Because this research is based on cross-sections of a rather large time horizon, the blockchain company studied herein was a semi-established blockchain startup - just a few years old at the time the first phase of this study explored the machinations of its external communication strategy. This strategy was a mix of channels that ranged from digital social media, e.g., Facebook, LinkedIn, etc., to more traditional means of communication, e.g., cold-calling, emails, etc. The objective of this study was to allow for a documentation of the effectiveness of channels used to develop a better understanding of how blockchain projects can not only amass a user base but also keep its own relative progress in check.

Furthermore, as this study was sandwiched in between the heydays of ICOs, and before the eventual mistrust that ended up surrounding these crowdfunding activities, it was found pertinent to study the ways in which a newly established startup would tend to tread the uncertain waters of the blockchain industry - an industry that was volatile at best.

\subsection{Research design}

This study was an exploratory case study conducted in two phases, wherein the first study was designed to be cross-sectional in nature conducted between November 2017 and April 
2018 focusing on the communications strategies employed by the company before and during its ICO proceedings. A second study was later conducted in 2021 exploring how the communications strategies were tweaked to ensure the product offerings were successfully received by consumers.

\subsubsection{Phase I: Strategies use pre-ICO and during ICO proceedings}

In the initial stages of this study, several early investors of the Credits platform were surveyed. Questionnaires were sent to a select number of investors using an online form and 254 participants responded back. These respondents ranged between the ages of 18-25 years (28.7\%), 26-34 years $(43.3 \%), 35-54$ years $(22.1 \%)$ and $55+$ years $(5.9 \%)$, and were mostly male $(65.3 \%)$ than female $(27.2 \%)$.

The respondents were geographically spread across various regions of the globe, with $40.9 \%$ from the Asian region, 28\% from the European region and 12.6\% from Australia and Oceania. The Americas with 9.8\% (mostly from the United States of America) and Africa with $8.7 \%$ were the regions with the least number of respondents.

a) Gender of respondents

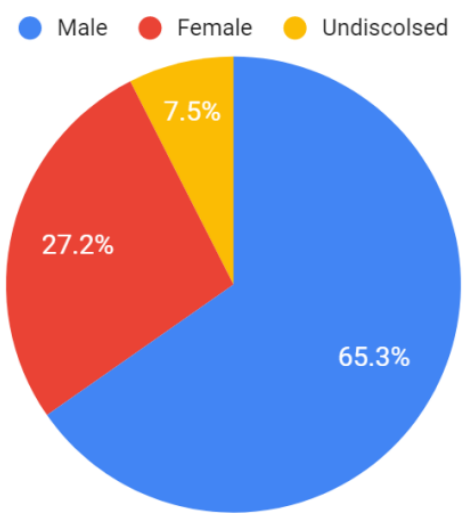

b) Geographic dispersal

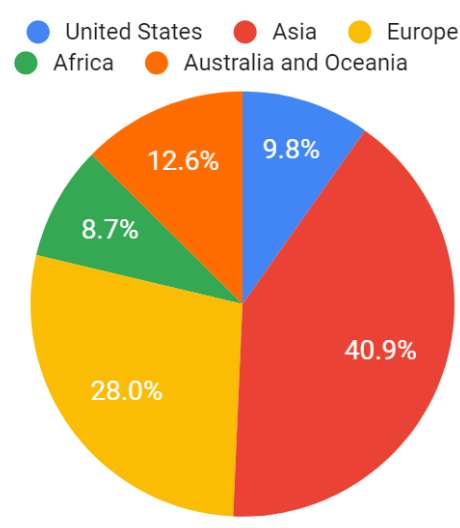

c) Age of respondents

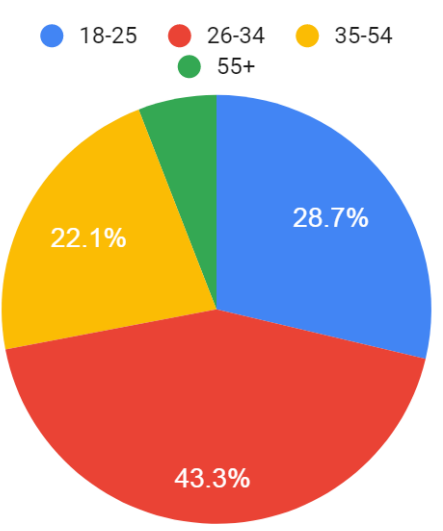

Figure 1: Demographics for the survey respondents

These respondents were presented with survey questionnaires that used psychometric scales, like the Likert scale, to scale and quantify responses in the survey. Questions include whether or not the respondents had sufficient knowledge of the blockchain industry, or how satisfied respondents were with the quality of communication with Credits, etc. It was believed that using these metrics before the ICO and during the ICO proceedings, the researcher would be able to better understand how blockchain companies subtly tweak their communication strategies in the initial stages to appeal to a broader base of investors.

\subsubsection{Phase II: Strategies currently in use}

Credits built itself as a platform to be used by developers. The initial communication strategies included detailed technical descriptions of the platform and catered mostly to the hardcore developers. With the passage of time, the blockchain company realised the potential in simplification of their communication strategies in order to be more acceptable to a broader user base. In this phase, we explored the various decisions that the company made to improve upon their communication strategies. 


\section{Findings and results}

In order to collect quantifiable primary data, we conducted several surveys. The questions were designed to be administered to the intended participants through the internet. Where the surveys were used to accumulate quantitative data, we also factored in qualitative data using structured interviews with participants. The survey questionnaires largely measured the quality of the external communications strategies in practice at Credits and also presented a pivotal insight into the Credit platform's user demographics, further classifying potential investors. The questionnaires were sent to various people and 254 people responded by filling out questions as discussed below.

\subsection{Phase I findings}

It was noted that more than half of the respondents answered that they had sufficient knowledge about the blockchain industry $53.9 \%$, whereas $13.8 \%$ answered that they were well-versed with the industry but dabbled very little in products such as the one being offered by Credits; $20.9 \%$ were at a stage that they felt this could be their initial foray into the blockchain world, and the remaining $11 \%$ of the audience didn't know about the industry at all. Because in the pre-ICO stages, investors and users alike are predominately unaware of how prolific a system would eventually be, yet if the investors are at the very least technically adept with the intricacies of blockchain projects, they're inclined to invest in the project based on the merits of the technology itself. Whereas a non-technical investor would largely impart greater focus on understanding what returns they may get on their investments.

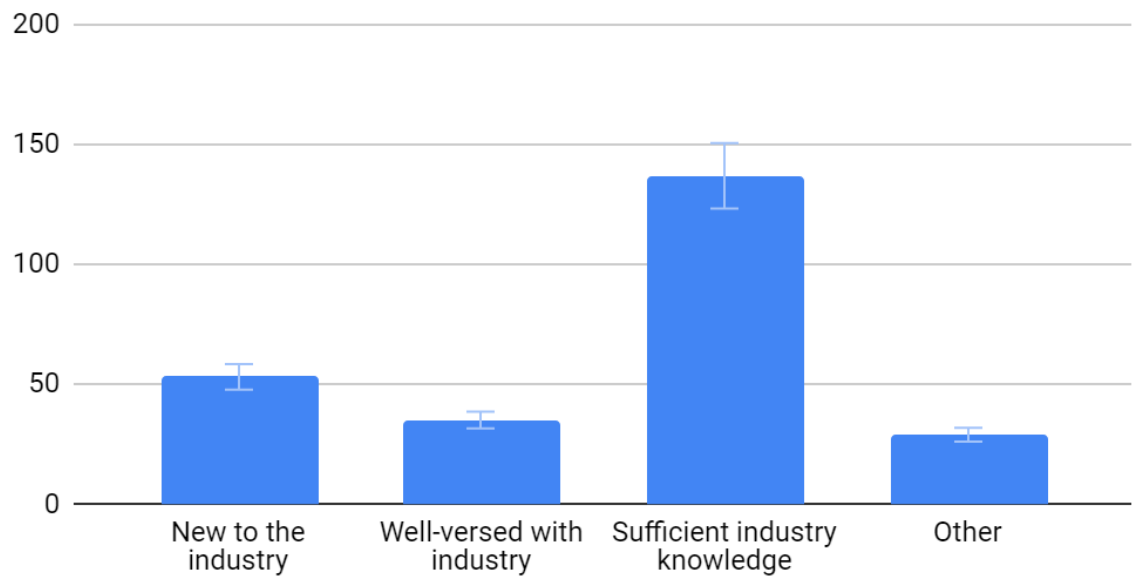

Figure 2: Respondents' knowledge about the blockchain industry

The Credits platform flaunted a structured upgrade to the ability of a traditional blockchain to cater a high volume of peer-to-peer financial transactions per second - a concept that was thoroughly defined in the technical documentation for the project. Although the team was well on its way to construct a prototype and a minimum viable product (MVP), they found it necessary to cater to the technical investors more so than the non-technical ones. Most of the Credits team were technically adept at development and it was evident in the documentation that was used to first attract such investors. The team found it easier to translate their vision into technical terms rather than embellishing future ROIs.

It was observed that communicating a project to an audience without the need for translation into business-driven jargon is detrimental to some degree but may attract true project backers that may certainly be sincerely invested in the project. However, if this ICO was conducted anytime before or after the period in which they did, i.e., before the rise of and the eventual disdain of ICOs, the project would have suffered a lot. The small numbers of people investing 
for the first time in any blockchain were a mere group of investors prospecting for returns and found it relevant to ride the bandwagon rather than go against the tide.

It therefore became important to analyse whether the documentation that was largely developed to cater to a larger audience was actually winning some non-technical investors as well. Or, was it merely a recipe for disaster in this regard. It was seen that contrary to the investors' belief about what they knew about the blockchain industry itself, not many were satisfied with the documentation at first with $7.9 \%$ completely satisfied, with about $44.5 \%$ mostly satisfied with the documentation. While $29.1 \%$ were unsure about where the project was headed, $15.7 \%$ were not satisfied and $2.8 \%$ were highly unsatisfied.

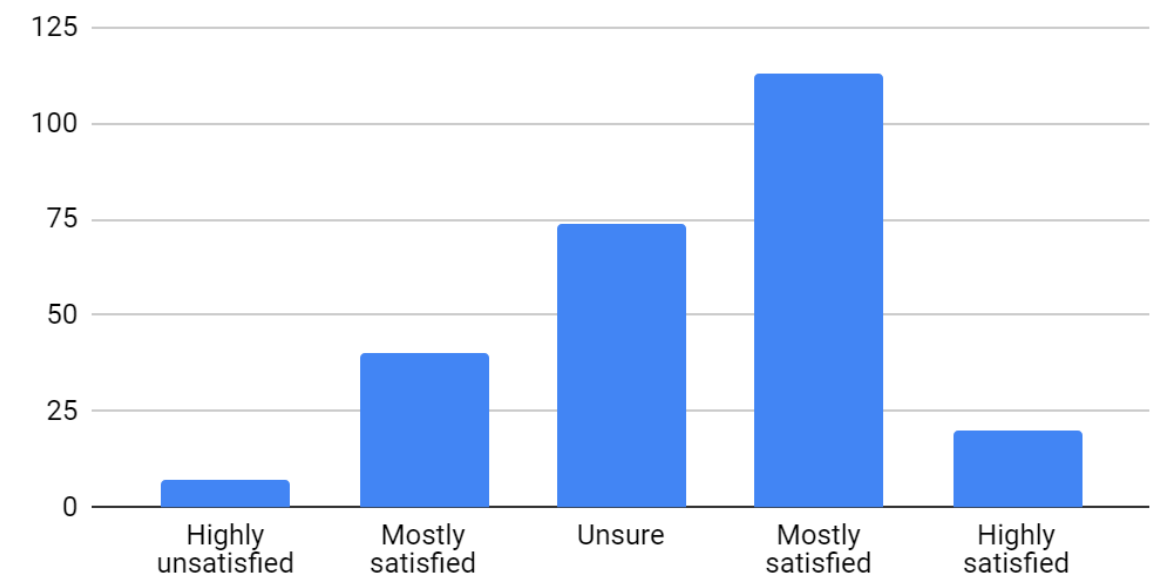

Figure 3: Respondents' satisfaction with documentation

It is at this point in time that the company decided to change its communication strategies for the very first time. Alongside a technical paper, the company published a one-pager document that elaborated on the utility aspects of the tokens and how they could bring in ROI once the project would be completed. The messaging bordered upon an idealist projection of the project's future. As we'd learn later, this did manage to improve the project's acceptance and eventually its adoption.

External communication channels that were used by the company ranged from social media channels to referral websites to organic search-engine optimisation and although $61.4 \%$ of investors learnt about the project through some form of social media and messaging channels, i.e., Telegram (87.8\%), Facebook (61.4\%), Twitter (72\%), and LinkedIn (35\%), almost $18.1 \%$ learnt about the project through referral links. It seemed that early investors, particularly those riding the ICO bandwagon, thought to diversify their investment by participating in referral programmes. Roughly $8.3 \%$ came to know about the project through organic searches.

Once invested in the project, these investors tended to then communicate with the project team mostly through email (46.1\%), Telegram (42.5\%), LinkedIn (4.3\%) and Facebook $(2.8 \%)$. There were about $2.8 \%$ investors that did not find a reason to get back in touch with the development team or the project owners. Investors were mostly satisfied with communicating the team directly through these channels, whereby $13.6 \%$ were completely satisfied; $53.1 \%$ were somewhat satisfied; $25.2 \%$ were neutral; the remainder were unsatisfied to varying degrees. 


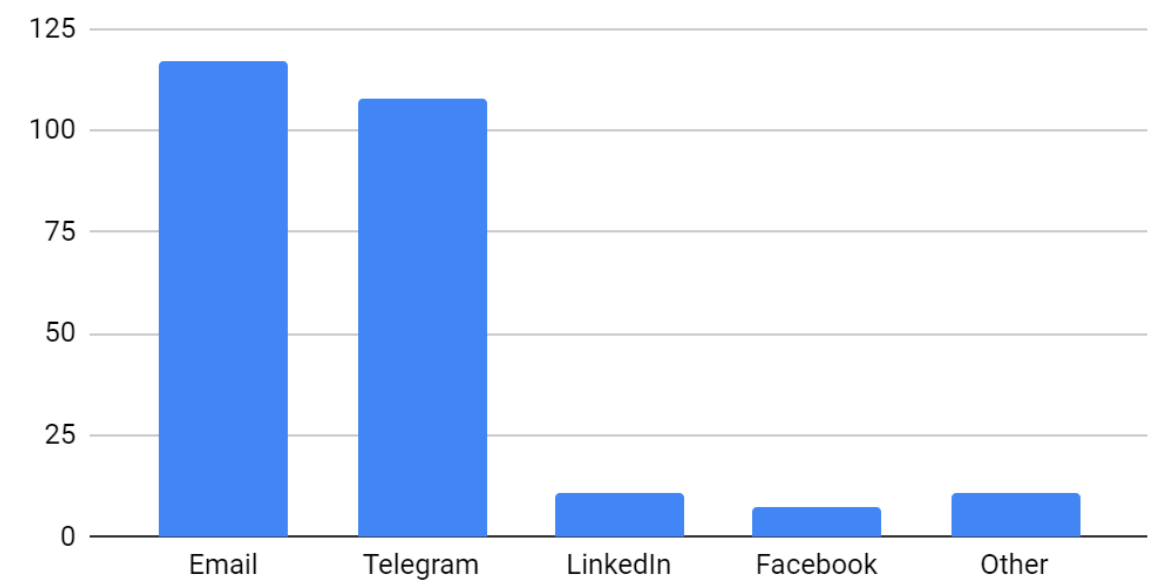

Figure 4: How investors communicate with project teams

It was at this point in time that Credits began to diversify its staff and bring in talent that could help them communicate with their investors as and when required. They subsequently branched into incorporating more communication channels to the mix. This eventually led to about $54.3 \%$ of investors willing to spread the word about the Credits platform, compared to $37.8 \%$ investors that didn't fully convert, leaving out $7.9 \%$ investors who felt they wouldn't recommend the project to others at all.

\subsection{Phase II findings}

Since the ICO and initial MVP offering, the company focused on delivering on its promises. It is here that we see a dramatic shift in the way messaging is communicated to investors and the company's user base. Instead of detailed and comprehensive documentation, the company started using user guides hosted on GitHub to further ease the users' adoption and acceptance rates. Not every user finds the need to be well-versed in the technical intricacies of how a peer-to-peer based blockchain platform works. They simply want it to be functional to cater to their needs. Ipso facto, the users primarily just want to be able to know the least possible mechanisms to be able to operate upon and use the particular blockchain platform or project. The question that lies herein is whether the company could have adopted this approach prior to its ICO. It feels quite relevant to address here that companies primarily indulge in crowdfunding activities like ICOs or bonus buybacks to amass an initial user base which in turn attracts further adoption of the blockchain platform. If a blockchain project doesn't show wide adoption rates in its initial stages, late adopters find it worthless to invest in a technology that doesn't attract people. Where projects like these attract initial investors by constantly messaging favourable returns on investments, a sustainable growth can only be attained if late adopters are made aware of the promise in the system by sharing with them the numbers of people already invested in the project either by showing them the market trading volumes or liquidity dynamics.

Hence, over time, Credits changed its messaging focusing less on returns on investment but rather on the numbers of users currently engaged with the system. This, as Credits rightly observed, is what eventually translates into trust in their platform and accelerates growth overall. However, this strategy can only be employed after a certain threshold of traders and trading volume has been achieved.

Credits marketed their platform as a suite of solutions that users could integrate into their solutions using an application programming interface (API) offering. An API is a piece of code that is exposed for other developers to build upon. Offering an API helped encourage users of the Credits platforms to work in tandem with the development of the platform and spurred innovation at each developmental phase of the project. 
However, one crucial factor that was identified here was the startup's efforts in trying to make their platform work with other platforms, cryptocurrencies - a concept known as interoperability. By ensuring that their platform could interact with other platforms through the creation of synergistic applications, Credits ensured that its users found value in their platform. Credits worked to include more integration such as stablecoins that helped the company grow its user base even further.

\subsection{Results}

As was evident throughout the course of this study, there is no communication strategy that could single-handedly weather the ever-evolving nature of the blockchain industry. In fact, it almost certainly suits any blockchain startup to revise and improve upon their communication strategies. With this study, it gave us the opportunity to observe one entire lifecycle of such revisions to an existing communications strategy. Our observations could be broken down into four distinct phases that employ communications strategies and messaging:

\section{Before crowdfunding}

At this particular point in time, startups should try and attract as many investors as possible. Technical projects should be drafted into documentation that is both technical and easily digestible for both investors that are well-versed with those technical details and those that are not.

\section{During crowdfunding}

Gone are the days when ICOs were a buzzword and brought droves to any manner of blockchain project. During crowdfunding, communication should rely on how promises would be shaped into reality; how what the investors are investing into may as well bring in good returns. However, the most crucial aspect here is building trust that the startup is actually steering towards success - an appropriately timed prototype or MVP launch may as well complement a well-designed communication strategy here and almost serves as a part of the strategy itself.

\section{After crowdfunding}

Once the startup has acquired the funding it requires, nothing else can ensure success than delivering on promises. Promises that are just that usually find disfavour amongst investors. It serves a startup better to stay in communication with their investors on the progress they're achieving. However, what we've found to be an effective indicator of success is the rollout of interoperable means of integrating the project into any solution that the investors intend to use it as. For a project like Credits, it meant ensuring that the project code was developed as an API so it could be integrated with the users' own systems. For Credits, interoperability also meant ensuring that their platform worked in synergistic conjunction with their users' products.

\section{Sustainable growth}

Once a project reaches critical mass in its user base, a blockchain startup seldom has to rely on promoting ROI figures or marketing communications projecting a vision of growth; their user base itself is a testament to their success.

\section{Conclusion}

The blockchain industry has been around for quite some time and as the technology matured so did the way projects based on the technology were marketed to potential investors. Scammers violated investors' trust by promising more than what they could deliver or creating elaborate schemes that baffled and bamboozled many investors into thinking these projects were viable. On the other hand, there were genuine projects that suffered as a result; their communications strategies were laid to rest. We looked at how it is important for blockchain startups to ensure that they're constantly revising and updating their 
communication strategies to ensure that they not only keep their investors' and users' trust but also deliver on a project that truly dismantles and disrupts the traditional systems by bringing in a challenging new and revolutionary product offering.

It was identified that there are a few concrete phases in the development of a blockchain project and its simultaneous efforts to accumulate capital whereby a startup's communication strategies holds the potential to be revised and then repurposed to cater to the changing needs of the projects. Sustainable growth can only be achieved if a project reaches critical mass, an increasing user base and a stable adoption rate. Communication strategies also find favourable results if coupled with the creation of minimum viable products and prototypes in the initial stages to include a synergistic interface to make the product interoperable with others' solutions.

\section{References}

Barnett, C. (2017, September 26). Inside the meteoric rise of ICOs. Forbes. https://www.forbes.com/sites/chancebarnett/2017/09/23/inside-the-meteoric-rise-of-icos/\# $6 \mathrm{~cd} 00 \mathrm{bca} 5670$

Brown, A. (2018, July 29). Initial coin offerings are getting a bad rap. Bloomberg. https://www.bloomberg.com/opinion/articles/2018-07-29/initial-coin-offerings-are-getting -a-bad-rap

Camilleri, E. (2016). Project success: Critical factors and behaviours. Routledge; 1st edition (February 28, 2011). ISBN 1317074866.

De Filippi, P., Mannan, M., \& Reijers, W. (2020). Blockchain as a confidence machine: The problem of trust \& challenges of governance. Technology in Society, 62, 101284. https://doi.org/10.1016/j.techsoc.2020.101284

Green, J. (2019, April 4). Building trust in the trustless: Blockchain's best asset is holding it back. Forbes. https://www.forbes.com/sites/jemmagreen/2019/03/31/building-trust-in-thetrustless-blockchains-best-asset-is-holding-it-back/?sh=248bb6d9768f

Lichfield, G. (2020, April 2). The problem with ICOs is that they're called ICOs. MIT Technology Review. https://www.technologyreview.com/2018/04/23/143440/theproblem-with-icos-is-that-theyre-called-icos/

Mackey, M. (2011, January 15). The devils who drove the financial meltdown of 2008. The Fiscal Times. https://www.thefiscaltimes.com/Articles/2011/01/15/The-Devils-WhoDrove-the-Financial-Meltdown-of-2008

Narayanan, A., Bonneau, J., Felten, E., Miller, A., Goldfeder, S. (2016). Bitcoin and cryptocurrency technologies: A comprehensive introduction. Princeton University Press. ISBN 1400884152.

Pietrewicz, L. (2018). Emerging trends in entrepreneurial finance: The rise of ICOs. Studia i Materiały, 27(1/2), 65-78.

Rosati, P., \& Čuk, T. (2018). Blockchain beyond cryptocurrencies. Disrupting Finance, 149170. https://doi.org/10.1007/978-3-030-02330-0_10

Samieifar, S., \& Baur, D. G. (2021). Read me if you can! An analysis of ICO white papers. Finance Research Letters, 38, 101427.

Sharma, T. K. (2019, September 6). Security Tokens vs. Utility Tokens: A Concise Guide. Blockchain Council. https://www.blockchain-council.org/blockchain/security-tokens-vsutility-tokens-a-concise-guide/ 